\title{
Management of Acute Myeloblastic Leukemias: The Experience of the Mother and Child Center of Chantal Biya Foundation, Yaounde
}

\author{
Pondy Ongotsoyi $\mathrm{AH}^{1,2^{*}}$, Kamdem Kengang BA ${ }^{2}$, Kedy Koum D³, Leverger G4, Atems Nkolata ${ }^{5}$, Ngo Nonga B 6
}

${ }^{1}$ Department of Pediatrics, Faculty of Medicine and Biomedical Sciences, University of Yaoundé I, Cameroon

${ }^{2}$ Chantal Biya's Foundation in Yaoundé Cameroon

${ }^{3}$ Faculty of Medicine and Pharmaceutical sciences, University of Douala Cameroon

${ }^{4}$ Hematology and Oncology, University Teaching Hospitals of Eastern Paris, France

${ }^{5}$ Department of Surgery University of Yaoundé I Cameroon

6Professor of Surgery, University of Yaoundé I Cameroon

\section{*Corresponding Author}

Pondy Ongotsoyi Angèle Hermine

\section{Article History}

Received: 04.09 .2019

Accepted: 16.09 .2019

Published: 30.09 .2019

\begin{abstract}
Background: Childhood cancer is a leading cause of death. Acute myeloblastic leukemia, the second leading cause of childhood leukemia, is not uncommon in Cameroon. Methods: We conducted a descriptive retrospective study in the department of Hematology Oncology in the Mother and Child Center of Chantal Biya Foundation, from March 2011 to February 2017 that is a period of 6 years. Results: We had 25 cases; the average age was 8 years with a sex ratio of 0.92 . The FAB classification found 9 cases of AML $1(36 \%), 6$ cases of AML $5(24 \%), 3$ cases of AML $3(12 \%), 3$ cases of AML $2(12 \%), 2$ cases of AML $4(8 \%)$ and $2(8 \%)$ cases unidentified. We treated 20 patients, $9(45 \%)$ had complete remission. The remission period was between 1 and 48 months, for an average of 20 months. The probability of survival for patients at 50 weeks was almost nil. Mean survival was 34 weeks with a confidence interval $(\mathrm{Cl})$ between $[10,157-58,718]$. Conclusion: The treatment is possible, but the absence of management constitutes a reason for abandonment of the treatment which makes the protocols not evaluable.
\end{abstract}

Keywords: Cancer, Cameroon, Child, Acute myeloblastic leukemia, Treatment.

\section{INTRODUCTION}

Acute myeloblastic leukemias (AML) are malignant hemopathies characterized by a clonal expansion of blasts of myeloid lineages and derived from the malignant transformation of a hematopoietic stem cell with impairment of their differentiation and apoptosis. AML accounts for $20 \%$ of acute childhood leukemia [1.2]. According to the FAB classification, 8 cytological subgroups, labelled M0 to M7 [3.4]. In Europe, according to the French national register in 2004, 770 cases of AML of children aged 0 to 14 were recorded over a 10-year period, given about 75 to 80 cases per year. This represented $17 \%$ of acute leukemia [5]. In sub-Saharan Africa, data is rare with respect to this pathology. In the hemato-oncology department of the Mother and Child Centre of Yaounde, acute childhood leukemias represent the second most represented cancer, after lymphomas. The aim of this study was to know the epidemiological, clinical-biological and therapeutic profile of patients with AML.

\section{Materials AND Methods}

This was a retrospective descriptive study within the Hemato-Oncology Department of the Mother and Child Centre of the Chantal Biya Foundation in Yaounde. This service is the only unit for the management of childhood leukemias Cameroon. Our population consisted of 25 cases of AML recorded from March 2011 to February 2017, for a period of 6 years. The data was collected from medical and patient records. In each sheet, we collected data on anthropometric parameters, admission dates, clinical and biological data, treatments and as well as patient evolution.

Copyright @ 2019: This is an open-access article distributed under the terms of the Creative Commons Attribution license which permits unrestricted use, distribution, and reproduction in any medium for non commercial use (NonCommercial, or CC-BY-NC) provided the original author and source are credited. 


\section{Patients}

An operating sheet was provided for each patient during the analysis of the medical records. This allowed for the identification of the epidemiological characteristics, date of admission to the ward, clinical information upon admission of the patient (signs and symptoms found on clinical examination).

Biological examinations such as hemogram and myelogram for the diagnosis and classification of leukemia type were also explored as much as other biological examinations in search for acute complications related to the disease. When a lumbar puncture was done, the presence of the blasts was sought. We noted results, when it was possible to run an HIV serology, as well as hepatitis Band $\mathrm{C}$ serologies

Therapeutically, the date of initiation of chemotherapy treatment, the type of protocol used, the date of initiation of each treatment and the number of treatments administered were sought.

Complete remission was defined by a normal clinical examination (regression of initial signs and symptoms), satisfactory

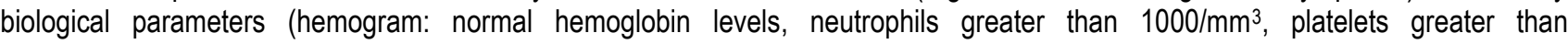
$100,000 / \mathrm{mm}^{3}$ and an absence of blasts). There was no end-of-induction myelogram.

Defaulters were defined as any patient who did not return to receive the scheduled treatment. Lost to follow-up was any patient who after the end of treatment did not return to follow-up consultations.

\section{Treatments}

Two protocols were used in the treatment of patients. We denoted X1 as the first protocol and X2 the second protocol, (which eventually replaced the first). The X1 protocol consisted of 2 induction and 2 consolidation cures.

The induction drugs were Aracytine $200 \mathrm{mg} / \mathrm{m} 2 /$ day day1, day2, day3, Doxorubicin $25 \mathrm{mg} / \mathrm{m} 2$ day1, and triple Intrathecale with Depoedrol, Aracytine, Methotrexate day1, day7 and Thioguanine $100 \mathrm{mg} / \mathrm{m} 2 /$ jday1 to day7. The consolidation drugs were Etoposide: $100 \mathrm{mg} / \mathrm{m} 2 /$ day, day1-day2, day8-day9, day15-day16 and Purinethol: $50 \mathrm{mg} / \mathrm{m} 2 /$ day, day 1 to day 28.

The X2 protocol consisted of an Induction using Aracytine: $200 \mathrm{mg} / \mathrm{m} 2 /$ day, day 1 to day 7, Daunorubicine: 40mg/m2/j day 1, day 2 or Doxorubicin: $25 \mathrm{mg} / \mathrm{m} 2$ day 1 , day 2 and Triple Intrathecale with Depoedrol, Aracytine, methotrexate day 1 , day 7 . Consolidation 1 consisted of Aracytine: $3 \mathrm{~g} / \mathrm{m} 2 \times 2 /$ day day 1 to day 3 and Daunorubicine: $40 \mathrm{mg} / \mathrm{m} 2 /$ day day 1 , day 2 , day 3 . Consolidation2 consisted of Aracytine: $200 \mathrm{mg} / \mathrm{m} 2 / \mathrm{jr} \mathrm{J} 1$ to J4, Daunorubicine: $40 \mathrm{mg} / \mathrm{m} 2 / \mathrm{jr} \mathrm{J} 1$ to day 4 and Etoposide:100 mg/m2/ day day 1 to day 4. Finally, Consolidation3 consisted of Aracytine: $3 \mathrm{~g} / \mathrm{m} 2 \times 2 /$ day day 1, day 2, day 8 , day 9 and Asparaginase: 6000 $\mathrm{IU} / \mathrm{m} 2 /$ day day 2 , day 9.

The aim of these treatments was to improve the quality of life of patients who were approaching very advanced stages of the disease to slow the progression of the disease for children awaiting possible medical evacuation. After the first induction, the other protocol was based on the improvement of physical and biological parameters. For each of the two protocols, the administration of each phase was conditioned by the alleviation of aplasia.

\section{Statistical Analysis}

The primary endpoint were the types of AML according to the $F A B$ classification with secondary endpoints being the clinical presentations of patients at admission, adherence to treatment, discontinuation of treatment, complete remission and overall survival. The period of complete remission was estimated in weeks. It was defined from the date when complete remission was noted until the resumption of symptoms and/or abnormalities observed in the hemogram (attainment of different lines and onset of blasts). The data were analyzed by the software EPI info and survival was estimated using the Kaplan Meier method. For the realization of the curve, the variables date of death and the duration of occurrence of death from onset of treatment (estimated in weeks) were used.

\section{Results}

\section{Epidemiological aspects}

We recorded 25 cases of acute myeloblastic leukemias. Among our patients, we had 12 boys (48\%) 13 girls (52\%), given a sex ratio of 0.92 . The average age was 8 years with a minimum age of 1 year and a maximum of 15 years. In the age range between 1 and 5 years we had $7(28 \%)$ of patients including 2 under 2 years of age. Between 5 and 10 years old we had $9(36 \%)$ of patients and $9(36 \%)$ aged over 10 years. 


\section{Clinical characteristics}

With respect to the different symptoms found in our patients and their frequency, fever was the most common symptom (76\%), followed by asthenia (64\%). The mucous/skin hemorrhages represented $60 \%$, followed successively by weight loss (44\%) and anorexia (40\%). Bone and abdominal pain were found at an equivalent percentage of $32 \%$.

On physical examination, the general condition of our patients was impaired in $60 \%$ of cases and conserved in $40 \%$. Anemic syndrome was present in $80 \%$ of cases and was mainly represented as dermal-mucosa pallor, dyspnea and asthenia. $7(28 \%)$ patients manifested with a hemorrhagic syndrome consisting of skin-mucous hemorrhages (epistaxis, bleeding gums, red eyes, hemorrhagic bullae in the mouth, petechiae, and bruising). Bleeding gums represented the most common sign (35\%) (Table I).

The Tumor syndrome was observed in $17(68 \%)$ Patients, with Some patients having isolated tissue involvement, while others had multiple affected tissues at once. Adenopathy at different sites (cervical, inguinal, supra-clavicular and axillary) was the most common sign $(71.11 \%)$, followed by splenomegaly $(11.11 \%)$, unilateral or bilateral exophthalmia $(8.88 \%)$, hepatomegaly $(6.66 \%)$ and hypertrophy of the tonsils $(2.22 \%)$ (Table I).

Table-1: Distribution of patients with respects the clinical presentations: Tumor and hemorrhagic syndromes.

\begin{tabular}{|l|c|c|l|c|c|}
\hline Tumor syndrome & Total & percentage & $\begin{array}{l}\text { Hemorrhagic } \\
\text { syndrome }\end{array}$ & Total & Percentage \\
\hline $\begin{array}{l}\text { Peripheral } \\
\text { adenopathy }\end{array}$ & 32 & 71,11 & Gum bleeding & 7 & 35 \\
\hline & & & Buccal bullae & 5 & 25 \\
\hline Splenomegaly & 5 & 11,11 & Petechiae & 3 & 15 \\
\hline Exophthalmia & 4 & 8,88 & Epistaxis & 2 & 10 \\
\hline Hepatomegaly & 3 & 6,66 & Ecchymosis & 2 & 10 \\
\hline $\begin{array}{l}\text { Hypertrophic } \\
\text { tonsils }\end{array}$ & 1 & 2,22 & Red eye & 1 & 5 \\
\hline Total & 45 & 100 & & 20 & 100 \\
\hline
\end{tabular}

Pleural effusion syndrome as well as gum infiltration where found in a patient each.

\section{Biological characteristics}

Hemoglobin levels ranged from 4.3 to $11.4 \mathrm{~g} / \mathrm{dL}$ with an average of $6.98 \mathrm{~g} / \mathrm{dL}$ prior to treatment. Severe anaemia (hemoglobin levels - $8 \mathrm{~g} / \mathrm{dL}$ ), was found in $16(64 \%)$ patients while $7(28 \%)$ patients had hemoglobin levels between 8 and $10 \mathrm{~g} / \mathrm{dL}$, and $2(8 \%)$ hemoglobin levels between 10 and $11.9 \mathrm{~g} / \mathrm{dL}$. Normocytic normochromic anemia was present in $64 \%$ of patients, microcytic hypochromic in $20 \%$ of patients and macrocytic in $16 \%$ of patients. Leukocyte levels ranged from 400 to $290,410 / \mathrm{mm} 3$. We recorded $9(36 \%)$ casent of hyper-leukocytic AML, including 5 cases $(20 \%)$ major casent of severe hyperleucytosis. A severe thrombopenia with platelet levels of less than $20,000 / \mathrm{mm} 3$ were found in $6(24 \%)$ patients. Platelet levels ranging from 20,000 to $50,000 / \mathrm{mm}^{3}$ in $13(52 \%)$ patients, and $4(16 \%)$ patients with platelet levels between 50 and $150 \mathrm{G} / \mathrm{L}$

We found circulating blastosis ranging between $5 \%$ and $96 \%$ with an mean of $59 \%$. In $12(54.50 \%)$ patients, blasts levels were higher than $50 \%$.

Based on the results of myelogram, we observed 9 cases of AML $1(36 \%), 6$ cases of AML $5(24 \%), 3$ cases of AML 3 (12\%), 3 cases of AML 2 (12\%), 2 cases of AML 4 (8\%) and 2 (8\%) unidentified AML cases (Figure1).

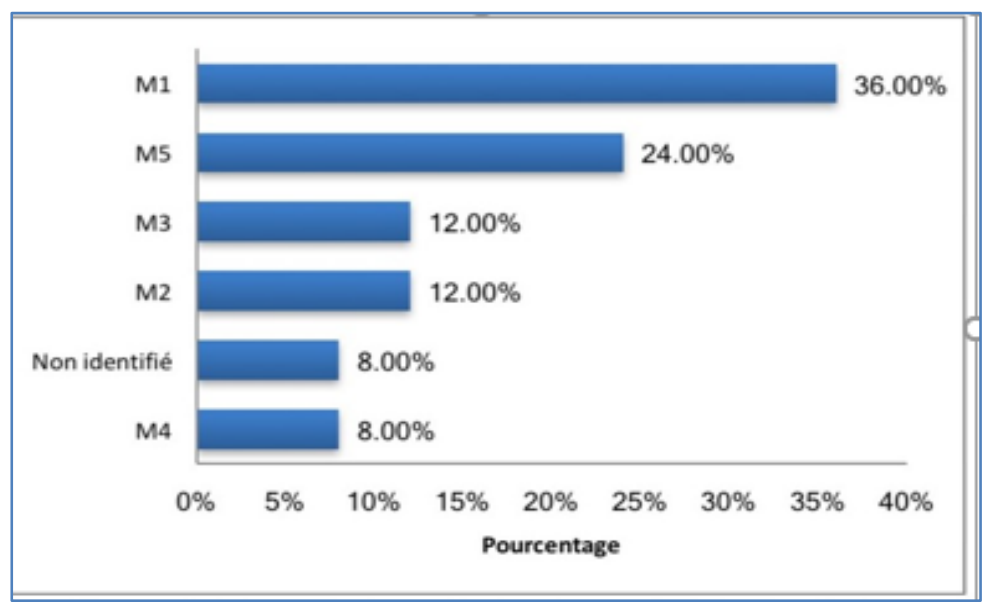

Fig-1: Distribution according to FAB classification 
Lumbar puncture was performed in $7(28 \%)$ patients and blast infiltration was present only in 1 patient. Tumor lysis syndrome, evaluated in 16 patients, was present in only 3 cases $(18.80 \%)$. We did not notice any cases of kidney failure. The LDH rate ranged from 600 to $31327 \mathrm{IU} / \mathrm{L}$ with a mean of $4411 \mathrm{UI} / \mathrm{L}$.

HIV serology performed systematically in all patients was positive in 1 patient. Viral hepatitis Band C serologies were done in $50 \%$ of our patients and were all negative.

\section{Therapeutic Characteristics}

Of the 25 patients, 3 died before treatment, 2 refused chemotherapy treatment and were eventually discharged. Chemotherapy treatment was given to 20 patients ( $80 \%)$ with a minimum of one cure and a maximum of 5 cures, with an average of 2 cures received by these patients.

X1 protocol was administered to $14(70 \%)$ and the X2 to $6(30 \%)$ Patients. Out of our 20 patients treated, $9(45 \%)$ had complete remission. The period of remission was between 1 and 48 months, with an average of 20 months. 8 patients benefited from the X1 protocol, meanwhile 1 patient received the $\mathrm{X} 2$ protocol. The average period of complete remission upon treatment was 7.5 weeks, with a minimum of 4 weeks and a maximum of 16 weeks. The probability of survival of patients at 50 weeks was almost nil. The average survival of patients was estimated at 34 weeks with a confidence interval (IC) between [10,157-58,718]. (Figure 2).

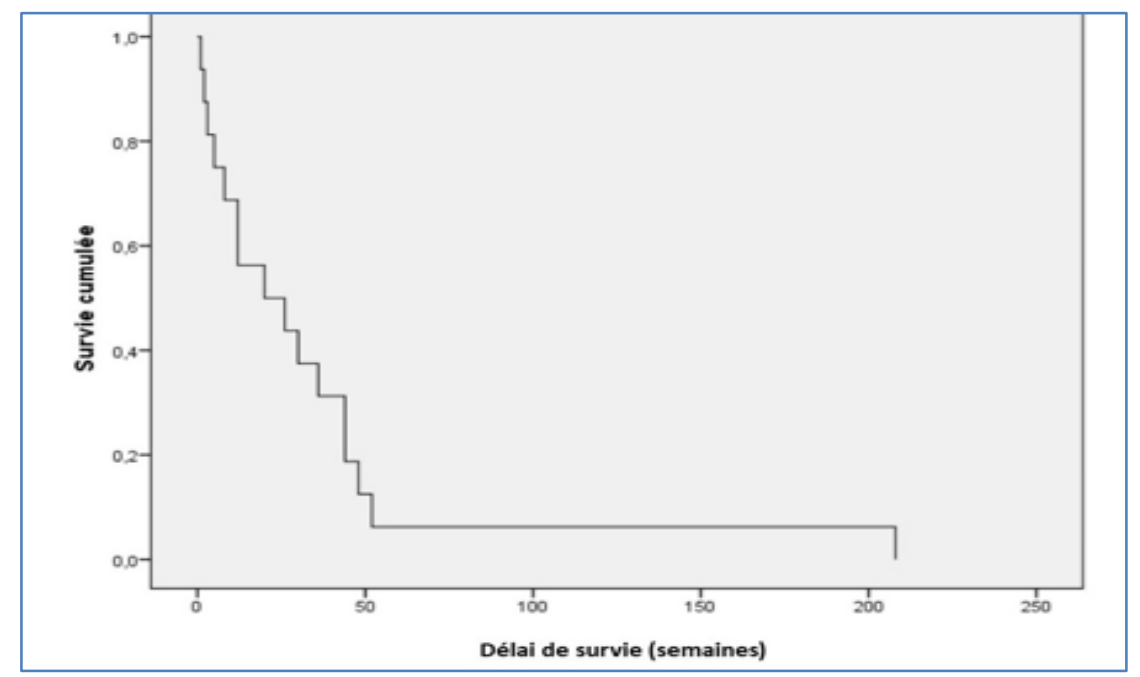

Fig-2: Survival curve

Of our 20 patients who started treatment, $10(50 \%)$ progressively abandoned treatment, while $10(50 \%)$ completed treatment. A total of 14 patients died, 1 patient alive and 5 others of whom we are still to hear from.

\section{Discussion}

Acute myeloblastic leukemia accounts for about $20 \%$ of childhood leukemia [1]. The incidence appears stable from birth to 10 years of age and increases slightly in adolescence [2].

\section{Epidemiological characteristics}

Age peaks in children with AML are observed before 1 year and after 10 years [6]. In our series, the average age was 8 years, we noted that $2(8 \%)$ patients were under the age of 2 years and $9(36 \%)$ patients over 10 years of age. Studies in some countries reveal that the peak of AML before the age of 1 year is much more pronounced. In Great Britain, for example, over a 10-year period, $15 \%$ of AMLs were between 0 and 1 year old [7]. In the French registers, they appear more frequent in children under 1 year of age at a rate of $42 \%$ [8]. We have not found studies done in sub-Saharan Africa on the epidemiology of AML, but we believe that this pathology is underdiagnosed

\section{Clinical characteristics}

The signs and symptoms of AML are related to blastic infiltration and spinal cord insufficiency of hematopoietic and extra hematological organs. Thus, in the clinical picture, we find fever, bleeding, asthenia, anemia, splenomegaly and hepatomegaly. Central nervous system involvement is characterized by intracranial hypertension, meningeal syndrome, convulsions, impairment of the cranial nerves and focal signs such as chloromas. Gum infiltration and leukemia are specific to AML, especially AML 4 and 5 . In our series, we found the different syndromes characteristic of the disease (anemic, hemorrhagic and infectious). However, we noted 
some signs and symptoms not found in the literature such as night sweats, weight loss, anorexia and abdominal pain. Were these a special presentation of the disease (night sweats) or the consequence of the evolution of the disease in a setting of malnutrition?

Le syndrome anémique était le plus fréquent et l'anémie était le premier motif de référence soit dans $60 \%$ des cas. Tous les patients à leur admission, avaient déjà reçu au moins une transfusion sanguine, des antipaludéens et des antibiotiques. Dans notre milieu, l'anémie est la conséquence d'un paludisme grave et lou d'une infection bactérienne. En l'absence des signes spécifiques de leucémie aigüe, la prise en charge de ces pathologies se justifie mais, c'est la multiplication de ces traitements sur l'histoire d'une même maladie qui montre que la pathologie est inconnue donc non diagnostiquée et la conséquence d'un retard de diagnostic.

Le syndrome tumoral apparaissait en deuxième position caractérisé majoritairement par des adénopathies à différents sites : cervicales, sus claviculaires, axillaires et inguinales. Cette présentation de la maladie dans notre série diffère des données de la littérature où le syndrome tumoral est variable et l'atteinte ganglionnaire est plus rare et réfère le plus souvent à la leucémie aigue lymphoblastique. L'infiltration gingivale a été retrouvée chez l'un de nos patients, atteint de LAM 4 (Figure 3) et les chloromes à localisation orbitaire chez 4 patients atteints d'une LAM 1 (Figure 4). Les chloromes dans la littérature sont habituellement retrouvés dans les cas de LAM 2 [9].

Anemic syndrome was the most common syndrome, while anemia was the primary reason for referral in $60 \%$ of the cases. All patients at admission had already received at least one blood transfusion, antimalarials and antibiotics. In our environment, anemia is the result of severe malaria and/or bacterial infection. In the absence of specific signs of acute leukemia, the management of these pathologies is justified, but it is the multiplication of these treatments on the history of the same disease that shows that the pathology is unknown and therefore undiagnosed and the result of a delay in diagnosis.

Tumor syndrome the second most frequent syndrome and was characterized mainly by adenopathy at different sites: cervical, clavicular, axillary and inguinal. This presentation of the disease in our series differs from that in literature where the tumor syndrome is variable and lymph node disease is rarer and most often confers to acute lymphoblastic leukemia. Gum infiltration was found in one of our patients with AML 4 (Figure 3) and orbital-located chloromas in 4 patients with AML 1 (Figure 4). Chloromas in the literature are usually found in cases of AML 2 [9].

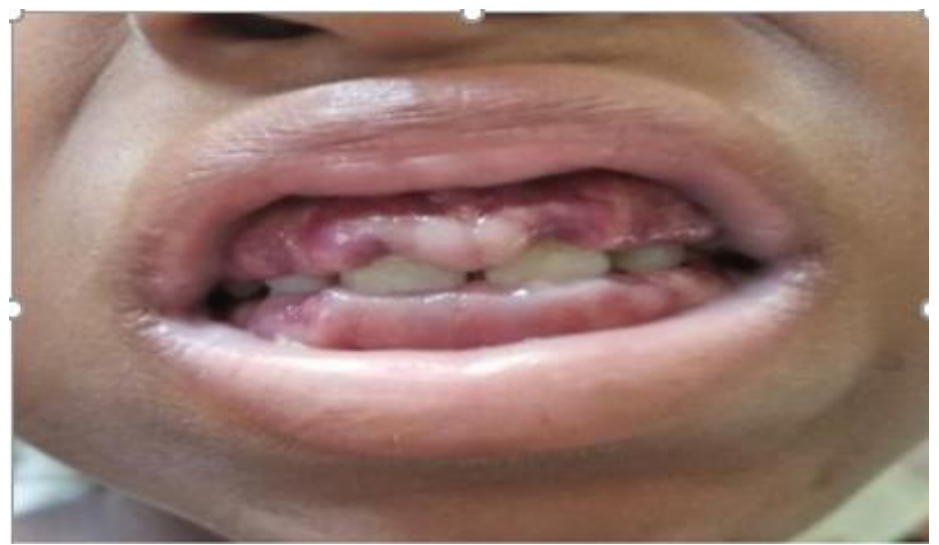

Fig-3: Gum infiltration in patient with AML4

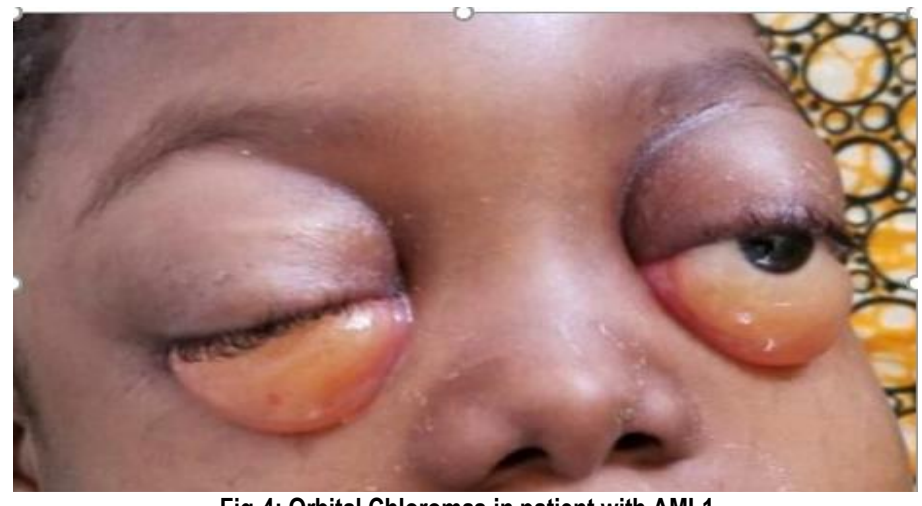

Fig-4: Orbital Chloromas in patient with AML1

Hemorrhagic syndrome in AML is a cause of early death. It is a hematological emergency because sometimes it is associated with coagulopathy. In our series, hemorrhagic syndrome was the third most frequent syndrome. Hemostatic disorders were 
not systematically sought. Some patients died due to bleeding for which DIVC could have been sought. In $28 \%$ of patients with hemorrhagic syndrome, $60 \%$ were cases of AML 1 and $30 \%$ were AML 3 . Patients with AML 1 all had hyper-leukocytic forms.

\section{Biological characteristics}

\section{The hemogram}

In the literature, anemia associated with acute leukemia is normocytic normochromic non regenerative and leukocytosis is variable [10]. In our series, $64 \%$ of patients had normochromic normocytic anemia while $20 \%$ had hypochromic microcytic anemia and $16 \%$ had macrocytic anemia. In the pathophysiology of cancer-related anemia, tumor cells can activate the immune system with release of cytokines that may lead to a reduction in the production of erythropoietin which may explain the normocytic normochromic anemia, as well as an abnormality of iron metabolism that in our environment can be due to nutritional deficiency, thus, explaining the cases of microcytic and macrocytic anemia. In Cameroon 33\% of children are chronically malnourished [11] and within our unit, 35.3\% of patients had moderate to severe acute malnutrition on admission, for which $30 \%$ had hypochromic microcytic anemia [12].

\section{Myelogram}

The tumor syndrome indicated a bone marrow aspirate and it was the analysis that enabled the establishment of a diagnosis with the morphology of the cells allowing for the FAB classification. In our population, the types found in order of frequency were AML $1(36 \%)$, AML $5(24 \%)$, AML $3(12 \%)$, AML $2(12 \%)$ and AML $4(8 \%)$. However, we have not found cases of AML 0,6 and 7 for which diagnosis requires the immunophenotyping technique that is not yet available in Cameroon. This classification differs from that found in a French series where AML 5 was the most common, followed by AML 2. AML 6 and AML 7 were represented at a low percentage [6]. In the Tunisian series [13] we found a more frequent distribution of AML 1, preceded by AML 2. Only the combination of cytology, immunophenotyping and cytogenetics can accurately define cytological subgroups.

\section{Metabolic work-up}

The pre-therapeutic assessment that combines a hemostatic work-up to role out DIVC, a metabolic work-up to prevent and monitor the complications of blast lyses [2] was not systematically sought in all patients. Tumor lysis syndrome was found in $18.80 \%$ of cases characterized by hyperuricemia sometimes associated with hypocalcemia, hyperkalemia and hyper phosphoremia. The infectious work-up was less alarming, as all these children arrived with antibiotic treatments.

\section{Therapeutic characteristics}

The diagnosis of AML in our unit led to two options, either therapeutic treatment in the option of medical evacuation or palliative treatment. Since care was not subsidized, families paid for the care of their children entirely, which would explain the high rate of defaulting during treatment. The protocols applied are derived from standard AML treatment protocols with a reduction in drug doses and adaptation of antimitotics based on local availability. Despite this reduction in doses, febrile aplasia was the main complication at each treatment and could last more than 20 days. This was a huge financial burden to families who did not have financial support. The time frames for administering the treatments were not met, however there were cases of complete remission, with a maximum of 48 months and an average duration of full remission of 20 months. This is a significant result in pediatric palliative care because children would have time to return home, with others the possibility of going back to school. Although the large number of patients in complete remission had received the $\mathrm{X} 1$ protocol, it was not possible to compare the two protocols due to treatment discontinuations.

\section{CONCLUSION}

Acute myeloblastic leukemia in children is a reality in Cameroon. The peak age found in our series was between 5 and 10 years with no patient under the age one year. Clinical and biological presentations have particularities. Treatment is possible, but the lack of care is a reason for abandoning treatment, thus resulting non-evaluable protocols.

\section{REFERENCES}

1. Harif M. Le cancer chez l'enfant, aspects pratiques. Juillet. 2012, 4: 39-41.

2. Kalifa C, Oberlin O, Pein F. Cancers de l'enfant. Flammarion Médecine-Sciences. 2008, 15 : 145-151.

3. Bennet JM, Catovsky D, Daniel MT, Flandrin G, Galton DA, Gralnick HR, Sultan C. (French-American-British (FAB) Cooperative Group). Proposals for the classification of acute leukemias. Br J Haematol. 1976;33:451-8.

4. Bennett JM, Catovsky D, Daniel MT, Flandrin G, Galton DA, Gralnick HR, Sultan C. Proposed revised criteria for the classification of acute myeloid leukemia: a report of the French-American-British Cooperative Group. Annals of internal medicine. 1985 Oct 1;103(4):620-5.

5. Registre National des Hémopathies Malignes de l'Enfant (RNHME), 1990-1999 J. Clavel, European Journal of Cancer Prevention. 2004.

6. G. LEVERGER.pdf [Internet]. [cited 8 nov 2017]. Disponible sur: https://formation.gustaveroussy.fr//courses/DIUOP/document/Module $\% 203 \% 20$ \%20LEUCEMIES\%20DE\%20L'ENFANT/Module\%203\%20-\%20LEUCEMIES\%20DE\%20LENFANT/G.\%20LEVERGER.pdf 
7. Leucémies-aigues-du-NRS.pdf [Internet]. [cité 8 nov 2017]. Disponible sur: http://www.oncobretagne.fr/wpcontent/uploads/2017/01/Leuc\%C3\%A9mies-aigues-du-NRS.pdf

8. Coste D, Bernard-Couteret E, Bernard JL. Les cancers dans le Sud-Ouest de la France. Bulletin Epidémiologique Hebdomadaire.1992; 52 : 243-244.

9. Robert S. Hillman, Kenneth A. Adult, Henry M. Rinder. Hématologie en pratique clinique. Flammarion -Médecine-Sciences. 2007, 17: $206-216$.

10. Creutzig U, Zimmermann M, Ritter J. Definition of a standard riskgroup in children with AML. Br J Haematol. 1999, 104: 630-639.

11. Jazet $E$, Wougang $R$. Etat nutritionnel, allaitement et pratiques alimentaires.In: Jazet $E$, dir.Enquete démographique et de santé et à indicateurs multiples (eds-mics).Yaoundé: Beltsville Drive. 2012: 159-65.

12. PONDY ONGOTSOYI, Angèle Hermine et al. Evaluation de l'État Nutritionnel chez les Enfants Atteints de Cancers Hospitalisés au Centre Mère et Enfant de Yaoundé. Health sciences and diseases. 19(4), 2018.

13. Braham-Jmili N, Sendi-Senana $H$, Khelif A. Leucémies aiguës myélö̈des en Tunisie: caractéristiques épidémiologiques et cliniques et classification OMS. J Afr Cancer Afr J Cancer. Février. 2010; 2(1):2532. 